\title{
The origin of oxygen in oxide thin films: Role of the substrate
}

\author{
C. W. Schneider, M. Esposito, I. Marozau, ${ }^{\text {a) }}$ K. Conder, M. Doebeli, Yi Hu, M. Mallepell, \\ A. Wokaun, and T. Lippert ${ }^{\text {b) }}$ \\ Department of General Energy Research, Paul Scherrer Institut, CH-5232 Villigen PSI, Switzerland; \\ Laboratory for Developments and Methods, Paul Scherrer Institut, CH-5232 Villigen PSI, Switzerland; \\ and Ion Beam Physics, ETH Zurich, CH-8093 Zurich, Switzerland
}

(Received 13 October 2010; accepted 23 October 2010; published online 11 November 2010)

\begin{abstract}
During the growth of oxide thin films by pulsed laser deposition, a strong oxygen substrate-to-film transfer has been experimentally observed for $\mathrm{SrTiO}_{3}$ and $\mathrm{LaAlO}_{3}$ thin films epitaxially grown on ${ }^{18} \mathrm{O}$ exchanged $\mathrm{SrTiO}_{3}$ and $\mathrm{LaAlO}_{3}$ substrates by secondary ion mass spectrometry depth profiling. This oxygen transfer effect can seriously change the respective thin film properties. Taking the oxygen substrate contribution to the overall oxygen balance into account, original ways to design material properties of oxide thin films can be envisioned like a controlled charge carrier doping of $\mathrm{SrTiO}_{3}$ thin films. (C) 2010 American Institute of Physics. [doi:10.1063/1.3515849]
\end{abstract}

The preparation of high quality complex oxide thin films and heterostructures with atomic precision has advanced in recent years considerably. ${ }^{1,2}$ Subsequently, the crystalline quality of these oxide films is comparable to semiconductors and oxide-semiconductors structures with designed properties have been prepared. ${ }^{3,4}$ These developments in thin film growth helped to investigate superconductivity in a single copper oxygen plane $^{5}$ or to prepare highly conducting oxide interfaces between two insulators ${ }^{6-8}$ which show superconductivity ${ }^{9}$ and magnetism. ${ }^{10}$ To obtain the desired oxide materials properties, a specific oxygen stoichiometry is essential. The challenge associated with growing oxides is to provide and control the amount of oxygen during the growth to obtain the desired oxygen stoichiometry and hence appropriate physical properties of the respective oxide. For a deposition using pulsed laser deposition (PLD), it often seems to be sufficient to create the correct amount of plasma species within an oxygen background to form the chosen compound as a thin film on a suitable substrate and to supply the missing oxygen with a subsequent annealing step.

During a deposition, the only discussed and usually considered oxygen sources are the target and the background gas. The substrate is taken as the template for the film to be and to match the respective lattice constants to grow the oxide film, e.g., epitaxially, with a preferred crystalline orientation. For an oxygen substrate contribution, there is so far only circumstantial evidence from $\mathrm{YBa}_{2} \mathrm{Cu}_{3} \mathrm{O}_{7-\delta}$ grown on $\mathrm{SrTiO}_{3}$ (Ref. 11) and EuO grown on YSZ. ${ }^{4}$ Growing oxides with, e.g., a perovskite structure, the dielectric $\mathrm{SrTiO}_{3}$ is a typically used substrate due to an acceptable lattice mismatch to most commonly investigated oxides. When doped with oxygen vacancies or metals $\mathrm{SrTiO}_{3}$ becomes a $n$-type ${ }^{12,13}$ or $p$-type conductor ${ }^{14}$ and a superconductor. ${ }^{15} \mathrm{Re}-$ cently, $\mathrm{TiO}_{2}$-terminated $\mathrm{SrTiO}_{3}$ (Ref. 16) served as a substrate for ultrathin $\mathrm{LaAlO}_{3}$ layers grown by PLD where the polar discontinuity at the $\mathrm{LaAlO}_{3} / \mathrm{SrTiO}_{3}$ interface ${ }^{17}$ causes a highly conducting $n$-type layer with charge carriers confined within a few $\mathrm{nm}$ at the interface. ${ }^{6,9,18,19}$ Oxygen vacan-

\footnotetext{
${ }^{a)}$ Present address: Department of Physics, University of Fribourg, Chemin du Musee 3, CH-1700 Fribourg, Switzerland.

b) Author to whom correspondence should be addressed. Electronic mail: thomas.lippert@psi.ch.
}

cies, caused by the PLD process itself, ${ }^{20}$ were briefly considered to be the origin of the observed conductivity. However, oxygen vacancies in $\mathrm{SrTiO}_{3}$ are highly mobile ${ }^{21}$ and to localize them exclusively at an interface seemed unlikely.

The example of $\mathrm{SrTiO}_{3}$ shows that the oxygen content plays a role for the respective material properties and it could even affect the properties of an oxide grown on it. This is revealed in Fig. 1 where the resistance of $\mathrm{SrTiO}_{3}$ thin films grown by PLD on (100) $\mathrm{SrTiO}_{3}$, (100) $\mathrm{LaAlO}_{3}$, and (100) oriented $\mathrm{MgO}$ single crystalline substrates at a vacuum background pressure $p$ of $1.5 \times 10^{-5}$ mbar, a fluence $F$, of $\sim 4 \mathrm{Jcm}^{-2}$ and a substrate temperature $T_{\mathrm{S}}$ of $750{ }^{\circ} \mathrm{C}$ were measured between 4 and $300 \mathrm{~K}$. After the deposition, the cooling-down took place at the vacuum base pressure. The sheet resistance of the $\mathrm{SrTiO}_{3}$ thin film on $\mathrm{SrTiO}_{3}$ clearly shows a metal-like temperature dependence, whereas $\mathrm{SrTiO}_{3}$ grown on $\mathrm{LaAlO}_{3}$ and $\mathrm{MgO}$ is semiconducting-like. The expectations have been to prepare $\mathrm{SrTiO}_{3}$ with similar transport properties using the same growth conditions on different substrates. A difference of $10^{6}$ at $4 \mathrm{~K}$ for the measured resistance

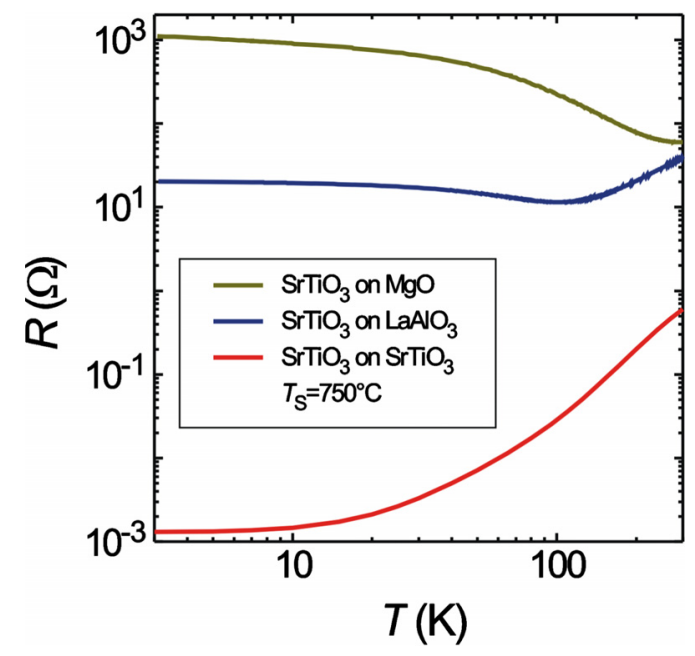

FIG. 1. (Color online) Temperature dependence of the sheet resistance of $\mathrm{SrTiO}_{3}$ thin films grown on (100) $\mathrm{MgO}$ (top), (100) $\mathrm{LaAlO}_{3}$ (middle), and (100) $\mathrm{SrTiO}_{3}$ (bottom) single crystalline substrates at $T_{\mathrm{S}}=750{ }^{\circ} \mathrm{C}$. All films are $\sim 100 \mathrm{~nm}$ thick and grown at a vacuum base pressure of 1.5 $\times 10^{-5}$ mbar, $F \sim 4 \mathrm{~J} \mathrm{~cm}^{-2}$, and a substrate temperature of $750{ }^{\circ} \mathrm{C}$. 
is unexpected and indicates a potential substrate contribution to the measured resistance. For $\mathrm{SrTiO}_{3}$ grown on oxygen deficient $\mathrm{SrTiO}_{3-\mathrm{x}}$, a metal-like temperature dependence can be expected. Estimating the oxygen content of the $\mathrm{SrTiO}_{3-\mathrm{x}}$ thin films using Rutherford backscattering (RBS), values of $\sim 2.5$ for the films shown in Fig. 1 have been obtained with an average composition of $\mathrm{Sr}_{0.97 \pm 0.03} \mathrm{Ti}_{1.03 \pm 0.03} \mathrm{O}_{2.52 \pm 0.06}$. This raises the questions where does the oxygen in an oxide thin film grown on an oxide substrate come from, is oxygen supplied by the substrate, and how significant is the oxygen transfer for deposition techniques other than PLD?

To investigate the role of oxygen supplied by the substrate during a deposition, the oxygen diffusion properties of $\mathrm{SrTiO}_{3}$ and $\mathrm{LaAlO}_{3}$ thin films grown on ${ }^{18} \mathrm{O}$ isotope exchanged $\mathrm{SrTi}^{18} \mathrm{O}_{3}$ and $\mathrm{LaAl}{ }^{18} \mathrm{O}_{3}$ substrates were studied by dynamic secondary ion mass spectrometry (D-SIMS) which yields elemental depth profiles. $\mathrm{SrTiO}_{3}$ and $\mathrm{LaAlO}_{3}$ thin films have been prepared at three different deposition temperatures (nominal room temperature, $650{ }^{\circ} \mathrm{C}$, and $750{ }^{\circ} \mathrm{C}$ ) by $\operatorname{PLD}(\lambda=248 \mathrm{~nm}, 10 \mathrm{~Hz})$ at a background pressure $p$ $=1.5 \times 10^{-5} \mathrm{mbar}$ and $F=4 \mathrm{~J} \mathrm{~cm}^{-2}$ on ${ }^{18} \mathrm{O}_{2}$ exchanged (100) oriented $\mathrm{SrTi}^{18} \mathrm{O}_{3}$ and $\mathrm{LaAl}{ }^{18} \mathrm{O}_{3}$ substrates (nonterminated and $\mathrm{TiO}_{2}$ terminated) with a total thickness of $\sim 100 \mathrm{~nm}$. Details to the oxygen exchange is given in Ref. 22. SIMS spectra were recorded using a quadrupole mass spectrometer (Hiden analytical EQS) operated with a 2.5 $\mathrm{keV} \mathrm{Ar}$ ion beam focused to $150 \mu \mathrm{m}$ diameter rastering over a square of $1 \times 1 \mathrm{~mm}$ with an effective sampling area of $500 \times 500 \mu \mathrm{m}^{2}$. The etched area is subsequently measured with a Dektak 8 profilometer to convert etching time into depth. In addition, a kinetic energy selection scheme is used to separate species with the same mass. ${ }^{23}$

The ${ }^{18} \mathrm{O}$ diffusion from $\mathrm{SrTi} i{ }^{18} \mathrm{O}_{3}$ into $\mathrm{SrTi}^{18} \mathrm{O}_{3}$ shows a pronounced dependence on the deposition temperature [Fig. 2(a)]. Whereas for a room temperature deposition, no traceable ${ }^{18} \mathrm{O}$ diffusion into the film has been measured, the situation changes dramatically for elevated deposition temperatures. At $650{ }^{\circ} \mathrm{C}$, there is considerable ${ }^{18} \mathrm{O}$ diffusion from the substrate into the film, while at $T_{\mathrm{S}}=750{ }^{\circ} \mathrm{C}$, there is no significant difference with respect to the amount of ${ }^{18} \mathrm{O}$ measured in the film and substrate. Measuring $\mathrm{Sr}$ and $\mathrm{Ti}$ species from the substrate and film simultaneously with ${ }^{16} \mathrm{O}$ and ${ }^{18} \mathrm{O}$, the elemental compositions of film and substrate are very similar. This implies that oxygen in the $\mathrm{SrTiO}_{3}$ thin film is supplied by the substrate and the oxygen provided by the target seems to play a minor role for this system.

The ${ }^{18} \mathrm{O}$ diffusion into $\mathrm{LaAlO}_{3}$ from $\mathrm{LaAl}{ }^{18} \mathrm{O}_{3}$ differs significantly compared to $\mathrm{SrTiO}_{3}$ on $\mathrm{SrTi}^{18}{ }^{18} \mathrm{O}_{3}$. No considerable oxygen diffusion from the substrate into the film is detected, in particular, at the interface region, irrespective of the studied deposition temperature (not shown). In the case of $\mathrm{SrTiO}_{3}$ grown on $\mathrm{LaAl}^{18} \mathrm{O}_{3}$, a significant and homogeneous oxygen contribution is measured for the $\mathrm{SrTiO}_{3}$ film prepared at $T_{\mathrm{S}}=750{ }^{\circ} \mathrm{C}$ [Fig. 2(b)]. Even at $650{ }^{\circ} \mathrm{C}$, there is still a significant ${ }^{18} \mathrm{O}$ intake which can be detected up to the film surface. It is interesting to note the comparatively large difference in oxygen diffusion properties of the $\mathrm{SrTiO}_{3}$ thin film considering a modest difference in $T_{\mathrm{S}}$ of $100{ }^{\circ} \mathrm{C}$. This is probably due to the activation energy of oxygen diffusion in $\mathrm{SrTiO}_{3}$ and that a film is inherently defect-rich which allows oxygen to diffuse more easily at elevated temperatures compared to a single crystal $\left[\mathrm{D}_{\text {crystal }}=10^{-15} \mathrm{~cm}^{2} \mathrm{~s}^{-1} ; \mathrm{D}_{\text {defects }}\right.$
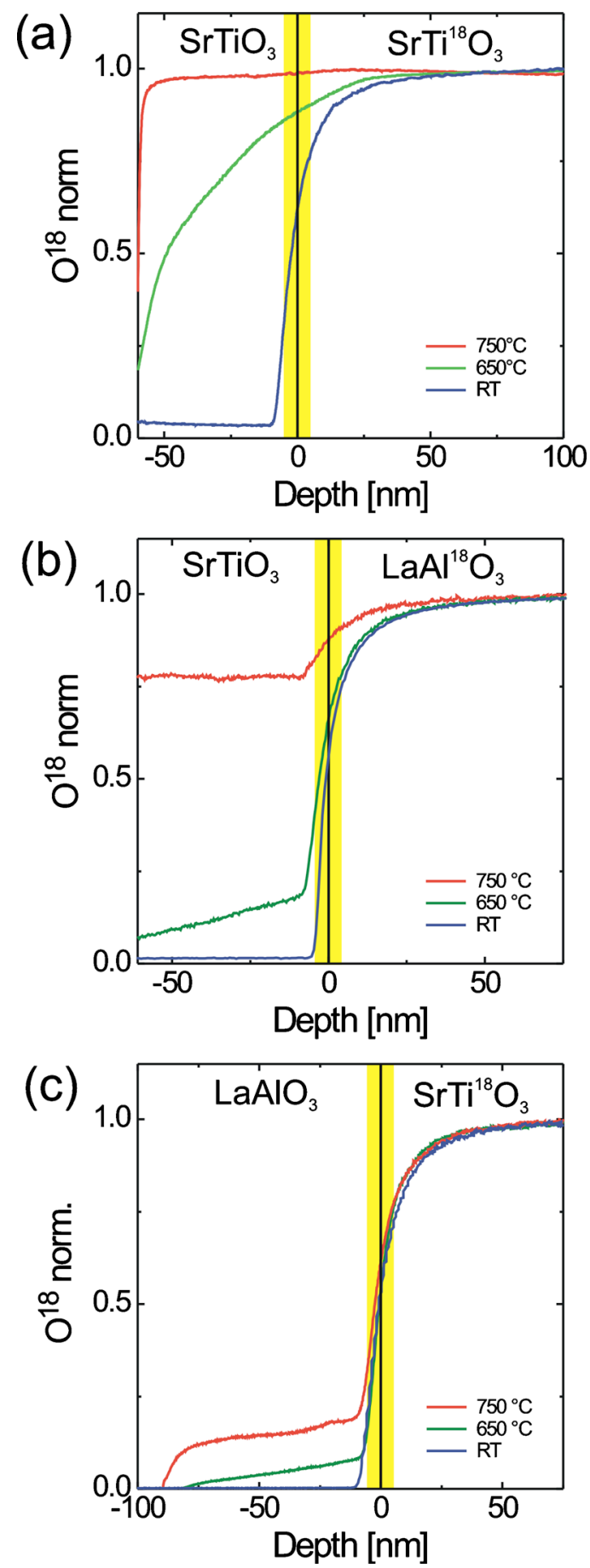

FIG. 2. (Color online) (a) ${ }^{18} \mathrm{O}$ SIMS depth profile of $\mathrm{SrTiO}_{3}$ on $\mathrm{SrTi}^{18} \mathrm{O}_{3}$ grown at $T_{\mathrm{s}}=750{ }^{\circ} \mathrm{C}, 650{ }^{\circ} \mathrm{C}$, and room temperature. The sharp drop of the ${ }^{18} \mathrm{O}$ signal near the $\mathrm{SrTiO}_{3}$ surface for the film grown at $T_{\mathrm{S}}=750{ }^{\circ} \mathrm{C}$ could be related to a back-exchange of ${ }^{16} \mathrm{O}$ at room temperature. (b) ${ }^{18} \mathrm{O}$ SIMS depth profile of $\mathrm{SrTiO}_{3}$ on $\mathrm{LaAl}{ }^{18} \mathrm{O}_{3}$ grown at $T_{\mathrm{s}}=750{ }^{\circ} \mathrm{C}, 650{ }^{\circ} \mathrm{C}$, and room temperature. (c) ${ }^{18} \mathrm{O}$ SIMS depth profile of $\mathrm{LaAlO}_{3}$ on $\mathrm{SrTi}^{18} \mathrm{O}_{3}$ grown at $T_{\mathrm{s}}=750{ }^{\circ} \mathrm{C}, 650{ }^{\circ} \mathrm{C}$, and room temperature. These samples have been grown at a vacuum base pressure of $1.5 \times 10^{-5} \mathrm{mbar}$ and a fluence of $\sim 4 \mathrm{~J} \mathrm{~cm}^{-2}$. The yellow area visualizes approximately the depth over which the information of the interface region is collected.

$=10^{-11} \mathrm{~cm}^{2} \mathrm{~s}^{-1}$ (Ref. 21)]. The large ${ }^{18} \mathrm{O}$ concentration in $\mathrm{SrTiO}_{3}$ thin films is unexpected if compared to $\mathrm{LaAlO}_{3}$ on $\mathrm{LaAl}{ }^{18} \mathrm{O}_{3}$. This suggests that $\mathrm{SrTiO}_{3}$ is a material which can either take or give oxygen during film growth, whereas $\mathrm{LaAlO}_{3}$ is more likely to keep oxygen during the deposition. Oxygen diffusion into $\mathrm{LaAlO}_{3}$ is more difficult to achieve 
than into $\mathrm{SrTiO}_{3}$. This becomes evident when depositing $\mathrm{LaAlO}_{3}$ onto $\mathrm{SrTi}^{18} \mathrm{O}_{3}$ [Fig. 2(c)]. The ${ }^{18} \mathrm{O}$ concentration in the $\approx 100 \mathrm{~nm}$ thin $\mathrm{LaAlO}_{3}$ films deposited at different temperatures is smaller than in $\mathrm{SrTiO}_{3}$, still there is a significant amount of ${ }^{18} \mathrm{O}$ at the film-substrate interface for the film grown at $T_{\mathrm{S}}=750{ }^{\circ} \mathrm{C}$.

The growth of oxide thin films by PLD is a process influenced by its plasma species formed during the ablation process (positive and negative ions, neutrals ${ }^{24}$ ), their kinetic energy and propagation velocity, and respective scattering events with a background gas. For a vacuum deposition, the only obvious oxygen source is the target. RBS measurements of these $\mathrm{LaAlO}_{3}$ films show that a substantial amount of oxygen is transferred from the target to the film, at the same time ${ }^{18} \mathrm{O}$ is supplemented from the substrate. The total amount of oxygen in the film is still smaller (approximately $\mathrm{LaAlO}_{2.9}$ ) as compared to the $\mathrm{SrTiO}_{3}$ substrate, indicating a substantial oxygen deficiency for the as-grown $\mathrm{LaAlO}_{3-\mathrm{x}}$ with induced vacancies in the substrate. The ${ }^{18} \mathrm{O}$ diffusion data have been reproduced, albeit with a reduced depth resolution by ERDA and essentially confirm the presented SIMS measurements. In addition, the diffusion data are independent of a substrate termination.

Frequently, electrical transport properties of as-grown oxides such as $\mathrm{LaTiO}_{3+\delta}$ on $\mathrm{SrTiO}_{3}$ and other substrates have been reported ${ }^{25}$ which yield similar variations in conductivity to the data in Fig. 1. Like $\mathrm{SrTiO}_{3}, \mathrm{LaTiO}_{3+\delta}(0 \leq \delta$ $\leq 0.5$ ) will most probably draw oxygen from the substrate if available which would explain the observed conducting properties. ${ }^{25}$ The additional substrate contribution is often eliminated if films are grown on oxides such as $\mathrm{MgO}$ or scandate substrates.

The work on the conducting $\mathrm{LaAlO}_{3} / \mathrm{SrTiO}_{3}$ interface shows that a combination of surface and interface engineering and controlled defect chemistry can give structure functionalities different from the bulk as shown for the conducting interfaces. Therefore, it seems possible to create structures where the controlled oxygen diffusion from or to $\mathrm{SrTiO}_{3}$ or related oxides helps to prepare multilayers with a defined oxygen defect structure. This is potentially beneficial for oxide multilayers used for thermoelectric applications where the contradictory demands between low thermal conductivity and good electrical conductivity could be reduced by creating defect-rich interlayers leading to an enhanced conductivity. Also, the presented experiments are most likely not just restricted to PLD because the general diffusion kinetic of a substrate-film structure is not restricted to a specific deposition technique. Details will be different, but the deposition of a material which can take oxygen during the deposition will typically result in oxygen redistribution between substrate and film. To achieve the desired properties, the specific deposition conditions for the chosen deposition technique need to be adjusted accordingly.

In summary, we have demonstrated that the oxygensubstrate contribution has to be taken into the overall oxygen balance when growing oxide thin films. $\mathrm{LaAlO}_{3}$ and $\mathrm{SrTiO}_{3}$ thin films where deposited on ${ }^{18} \mathrm{O}$ exchanged $\mathrm{SrTiO}_{3}$ and $\mathrm{LaAlO}_{3}$ substrates and the ${ }^{18} \mathrm{O}$ diffusion profile studied by D-SIMS. A substantial oxygen transfer between substrate and as-grown thin film has been noted, which indicates that the initially formed film is oxygen deficient and a chemical gradient is in favor of supplying oxygen via the substrate. This finding should also be applicable to other deposition techniques such as molecular beam epitaxy or sputtering if high deposition temperatures are involved.

This work was partially supported by SNF, Project No. 200020-117642, MaNEP, and the Paul Scherrer Institut. We also gratefully acknowledge fruitful discussions with A. Weidenkaff (EMPA), E. Pomjakushina, and P. Willmott (PSI).

${ }^{1}$ D. G. Schlom, J. H. Haeni, J. Lettieri, C. D. Theis, W. Tian, J. C. Jiang, and X. Q. Pan, Mater. Sci. Eng., B 87, 282 (2001).

${ }^{2}$ Pulsed Laser Deposition of Thin Films: Applications-Led Growth of Functional Materials, edited by R. Eason (Wiley Interscience, Hoboken, 2008). ${ }^{3}$ M. P. Warusawithana, C. Cen, C. R. Sleasman, J. C. Woicik, Y. L. Li, L. F. Kourkoutis, J. A. Klug, H. Li, P. Ryan, L. P. Wang, M. Bedzyk, D. A. Muller, L. Q. Chen, J. Levy, and D. G. Schlom, Science 324, 367 (2009).

${ }^{4}$ A. Schmehl, V. Vaithyanathan, A. Herrnberger, S. Thiel, C. Richter, M. Liberati, T. Heeg, M. Rockerath, L. F. Kourkoutis, S. Muhlbauer, P. Boni, D. A. Muller, Y. Barash, J. Schubert, Y. Idzerda, J. Mannhart, and D. G. Schlom, Nature Mater. 6, 882 (2007).

${ }^{5}$ G. Logvenov, A. Gozar, and I. Bozovic, Science 326, 699 (2009).

${ }^{6}$ A. Ohtomo and H. Y. Hwang, Nature (London) 427, 423 (2004).

${ }^{7}$ M. Huijben, G. Rijnders, D. H. A. Blank, S. Bals, S. Van Aert, J. Verbeeck, G. Van Tendeloo, A. Brinkman, and H. Hilgenkamp, Nature Mater. 5, 556 (2006).

${ }^{8}$ S. Thiel, G. Hammerl, A. Schmehl, C. W. Schneider, and J. Mannhart, Science 313, 1942 (2006).

${ }^{9}$ N. Reyren, S. Thiel, A. D. Caviglia, L. F. Kourkoutis, G. Hammerl, C. Richter, C. W. Schneider, T. Kopp, A. S. Ruetschi, D. Jaccard, M. Gabay, D. A. Muller, J. M. Triscone, and J. Mannhart, Science 317, 1196 (2007).

${ }^{10}$ A. Brinkman, M. Huijben, M. Van Zalk, J. Huijben, U. Zeitler, J. C. Maan, W. G. Van der Wiel, G. Rijnders, D. H. A. Blank, and H. Hilgenkamp, Nature Mater. 6, 493 (2007).

${ }^{11}$ L. S.-J. Peng, W. Wang, W. Jo, T. Ohnishi, A. F. Marshall, R. H. Hammond, M. R. Beasley, E. J. Peterson, and R. E. Ericson, IEEE Trans. Appl. Supercond. 11, 3375 (2001).

${ }^{12}$ Y. Tokura, Y. Taguchi, Y. Okada, Y. Fujishima, T. Arima, K. Kumagai, and Y. Iye, Phys. Rev. Lett. 70, 2126 (1993).

${ }^{13}$ H. P. R. Frederikse and W. R. Hosler, Phys. Rev. 161, 822 (1967).

${ }^{14}$ H. Guo, L. Liu, Y. Fei, W. Xiang, H. Lu, S. Dai, Y. Zhou, and Z. Chen, J. Appl. Phys. 94, 4558 (2003).

${ }^{15}$ C. S. Koonce, M. L. Cohen, J. F. Schooley, W. R. Hosler, and E. R. Pfeiffer, Phys. Rev. 163, 380 (1967).

${ }^{16}$ M. Kawasaki, K. Takahashi, T. Maeda, R. Tsuchiya, M. Shinohara, O. Ishiyama, T. Yonezawa, M. Yoshimoto, and H. Koinuma, Science 266, 1540 (1994).

${ }^{17}$ S. Okamoto and A. J. Millis, Nature (London) 428, 630 (2004).

${ }^{18}$ M. Sing, G. Berner, K. Goss, A. Muller, A. Ruff, A. Wetscherek, S. Thiel, J. Mannhart, S. A. Pauli, C. W. Schneider, P. R. Willmott, M. Gorgoi, F. Schafers, and R. Claessen, Phys. Rev. Lett. 102, 176805 (2009).

${ }^{19}$ M. Basletic, J. L. Maurice, C. Carretero, G. Herranz, O. Copie, M. Bibes, E. Jacquet, K. Bouzehouane, S. Fusil, and A. Barthelemy, Nature Mater. 7, 621 (2008).

${ }^{20}$ M. L. Scullin, J. Ravichandran, C. Yu, M. Huijben, J. Seidel, A. Majumdar, and R. Ramesh, Acta Mater. 58, 457 (2010).

${ }^{21}$ A. E. Paladino, L. G. Rubin, and J. S. Waugh, J. Phys. Chem. Solids 26, 391 (1965).

${ }^{22}$ C. W. Schneider, M. Esposito, I. Marozau, K. Conder, M. Doebeli, Y. Hu, M. Mallepell, A. Wokaun, and T. Lippert, "The oxygen contribution of the substrate for oxide thin film growth" (unpublished).

${ }^{23} \mathrm{H}$. Téllez, J. M. Vadillo, and J. J. Laserna, "Development of an energyresolved method for SIMS in-depth analysis of metal-polymer interfaces," Surf. Interface Anal. (to be published).

${ }^{24}$ M. Esposito, T. Lippert, M. Doebeli, C. W. Schneider, and A. Wokaun, "Negative ions: The overlooked species for oxide thin film growth using pulsed laser ablation" (unpublished).

${ }^{25}$ F. J. Wong, S.-H. Baek, R. V. Chopdekar, V. V. Mehta, H.-W. Jang, C.-B. Eom, and Y. Suzuki, Phys. Rev. B 81, 161101 (2010). 